\title{
EMMANUEL DELAPLANCHE, Louis-René des Forêts.
}

\section{Empreintes}

\section{Fabio Scotto}

\section{(2) OpenEdition \\ Journals}

\section{Edizione digitale}

URL: https://journals.openedition.org/studifrancesi/32253

DOI: 10.4000/studifrancesi.32253

ISSN: 2421-5856

\section{Editore}

Rosenberg \& Sellier

\section{Edizione cartacea}

Data di pubblicazione: 1 août 2020

Paginazione: 440-441

ISSN: 0039-2944

\section{Notizia bibliografica digitale}

Fabio Scotto, «emmanuel delaplanche, Louis-René des Forêts. Empreintes», Studi Francesi [Online], 191 (LXIV | II) | 2020, online dal 01 septembre 2020, consultato il 17 septembre 2021. URL: http:// journals.openedition.org/studifrancesi/32253 ; DOI: https://doi.org/10.4000/studifrancesi.32253

Questo documento è stato generato automaticamente il 17 septembre 2021.

\section{(9) $\odot \Theta \Theta$}

Studi Francesi è distribuita con Licenza Creative Commons Attribuzione - Non commerciale - Non opere derivate 4.0 Internazionale. 


\title{
EMMANUEL DELAPLANCHE, Louis-René des Forêts. Empreintes
}

\author{
Fabio Scotto
}

\section{NOTIZIA}

emmanuel DelaPlanche, Louis-René des Forêts. Empreintes, s.l., Éditions Publie.net, «Essais», $279 \mathrm{pp}$.

1 Fin dall'«Introduction» (pp. 15-22), l'A. rivela la ragione e lo scopo di questa sua ricerca su una delle figure più singolari della letteratura francese del Secondo Novecento, creatore, come afferma, di un'«œuvre économe et ramassée» che pur attirò l'attenzione dei maggiori del suo tempo, da Bataille a Sartre, da Quignard a Bonnefoy e a Blanchot, che nella sua Postfazione al romanzo Le bavard (1963) parlò di un «nihilisme presque infini [...] nihilisme de la fiction réduite à son essence, maintenue au plus près de son vide et de l'ambiguïté de ce vide». La radicalità fantasmatica della scrittura di des Forêts in quell'opera appare a Delaplanche emblematica dei problemi che da sempre essa pone, ovvero, da un lato, la difficoltà di «situer une œuvre», dall'altro, per via del suo statuto complesso di «lecteur-créateur», quello dell'intertestualità, dove «intertexte», precisa in una nota, va inteso come «l'ensemble des livres que des Forêts avait en tête ou dans les mains lorsqu'il s'est mis à écrire ses propres livres», con ciò intendendo sostanzialmente la sua «pratique d'emprunt» (p. 20).

2 Su queste premesse, le tre parti in cui è divisa questa monografia focalizzano questa tematica dell'interazione, ovvero il rapporto fra lettura e scrittura che non sorprende abbia interessato un critico come Maurice Blanchot, da sempre sensibile a quanto attiene alla dialettica insita nell'Entretien infini. Nella prima, «Un livre au milieu des livres», l'A. ben distingue fra plagio, prestito e allusione, intese come l'empreinte dell'altro su di sé e di sé sull'altro (duplice accezione cui pare presumibilmente alludere il titolo del volume), a indicare i meccanismi stessi messi in atto dalla maniera di scrivere di des Forêts; in particolare, è opportuno parlare nel suo caso di «plagiat 
créatif» (p. 27), che non si limita a riportare lacerti di testo altrui nel corpo del proprio testo, ma che li modifica per in-corporarli in una nuova tela creativa. Ne risulta più un atto implicitamente critico che non quello che Cioran chiamerebbe un mero exercice d'admiration. Infatti egli corregge, modifica, forse sulla scia della lezione lautréamontiana, che richiamava alla "necessità" del plagio. Di fatto, des Forêts è un autore che, come Montaigne, lavora nella sua biblioteca, la tiene, per così dire, accanto al tuo tavolo di scrittura, e, quanto alle pratiche intertestuali, l'A. fornisce, attraverso efficaci esempi con evidenziazioni, un interessante campione di una sorta di fenomenologia del prestito in des Forêts (da G. Picon e F. Dostoevskij, ad esempio, pp. 46-47). Proprio alla pratica del prestito è dedicata in approfondimento la seconda parte, «Comprendre l'emprunt», che pare inizialmente dovuta al potere di fascinazione che hanno le sue letture su di lui, fonte di un desiderio di imitazione che indurrebbe a scrivere «sous influences» (p. 57); qui altri illuminanti esempi di prestito appaiono quelli presi da G. Bataille, W. Faulkner e da A. Breton (pp. 68-76), e altri ne seguono da Hemingway, Caldwell, Sartre, Leiris, Kafka, il che fa dire a Delaplanche che «l'emprunt est une réponse qui permet aux textes d'être à la fois une alchimie de mots, et une alchimie des livres» (p. 142), modo forse di alludere anche all'«alchimie du verbe» rimbaudiana.

3 La terza parte, «Des fictions au cœur du secret», si sofferma sulle pratiche finzionali ne Les mendiants e Le bavard, dove dal rapporto fra la progettualità e la realizzazione emerge tutta una rete di referenti e referenze letterarie altre che fanno di questi testi una sorta di laboratorio sperimentale permanente sulla scrittura dalle forti implicazioni meta-letterarie, come è del resto, da Breton in poi, nella specifica natura di molto Novecento francese.

4 Nella «Conclusion» l'A., che confessa l'origine genetica della sua analisi (la quale però qui si limita al materiale edito, senza prendere in considerazione gli avantesti), ribadisce l'efficacia dell'analisi dell'intertesto per comprendere il «puzzle» dell'opera di des Forêts, il cui uso del plagio e del prestito vanno rivisti nella prospettiva creativa che fu la sua, ovvero una sorta di auto-analisi alla luce dell'altro, se «cette pratique montre le constant retour sur soi qu'opère des Forêts de livre en livre. Écrire c'est prolonger sans cesse son propre examen» (p. 258), pratica "antica", e proprio per questo "moderna", in quanto consapevole della parziale o totale tributarietà dal passato lontano o recente di ogni scrittura. 